\title{
CALIFICACIÓN DE REQUISITOS Y OBJECIÓN DEL REGISTRO EN EL PROCEDIMIENTO DE CONSTITUCIÓN JURÍDICA DE ENTIDADES RELIGIOSAS DE DERECHO PÚBLICO REGIDO POR LA LEY $N^{\circ}$ 19.638*
}

\author{
JORGE DEL PICÓ RUBIO**
}

RESUMEN: Este trabajo aborda uno de los problemas jurídicos más relevantes que involucra el proceso de constitución jurídica de las entidades religiosas en Chile, que pretendan su reconocimiento como personas jurídicas de Derecho público, en el marco brindado por la Ley 19.638, referido a los requisitos de procedencia, la calificación de los mismos y los efectos del supuesto de objeción de la inscripción en el registro público del Ministerio de Justicia, por parte de una organización religiosa. En especial, centra la atención del análisis en el proceso de revisión administrativa de los antecedentes de la organización requirente, el carácter meramente formal o sustantivo de dicho examen, el supuesto de objeción al registro, los efectos jurídicos de su procedencia, la superación de la objeción, la firmeza del registro y el consiguiente nacimiento de la entidad a la vida del Derecho. La exposición ordenada del tema, el planteamiento de los problemas jurídicos anexos y de la mejor manera de abordar las posibles soluciones, contribuye a brindar claridad a una de las materias más debatidas y de mayor complejidad del sistema implantado por la Ley de cultos en Chile.

PALABRAS CLAVE: Derecho y religión - Ley de cultos - Constitución jurídica de personas de derecho público - Registro de entidades religiosas.

\section{DESCRIPTION OF THE REQUIREMENTS AND OBJECTION OF THE REgISTRY IN THE PROCEDURE OF LEgAL CONSTITUTION OF Religious ENTITIES OF PUBLIC LAW GOVERNED BY LAW $\mathrm{N}^{\circ} 19.638$.}

ABSTRACT: This article deals with one of the most relevant juridical problems involved in the process of legal constitution of religious entities

\footnotetext{
* Fecha de Recepción: 10 de octubre de 2011. Fecha de aceptación: 6 de julio de 2012.

** Doctor en Derecho de la Universidad de Zaragoza. Profesor de Derecho Civil y Ciencias del Derecho en la Universidad de Talca.
} 
in Chile that seek admission as artificial persons of public law, within the framework of law 19.638, referred to the justification requirements, the qualification of them, and the objection supposition effects of the recording in the public registry of the Ministry of Justice, performed by a religious organization. It particularly centers its attention in the process of background administrative review of the requiring organization; the merely formal or substantive character of said review; the objection supposition of the registry; the juridical effects of its legal basis; the overcoming of the objection; the strength of the registry, and the subsequent birth of the entity to the legal system. The orderly manner of exposing the subject, the proposal of juridical problems attached and the best way to deal with possible solutions, clearly contributes to one of the most debated and highly complex issues of the system set forth by the Religious Worship Law in Chile.

KEY WORDS: Law and religion - Religious Worship Law - Legal constitution of artificial persons of Public Law - Religious entities registry.

\section{INTRODUCCIÓN}

La reciente conmemoración del Duodécimo aniversario de la entrada en vigor de la Ley $\mathrm{N}^{\circ} 19.638$, que dicta normas sobre la constitución jurídica de las entidades religiosas, constituye sin duda un hito significativo en la complejización de nuestro Derecho nacional, que convoca a revisitar una normativa legal de gran significación en la apertura de nuevos espacios de libertad ciudadana, en particular por su aporte a la consagración jurídica del principio de libertad religiosa en Chile ${ }^{1}$.

Este cuerpo legal, conocido como "Ley de cultos" (LC), modificó la situación jurídica precedente en materia de constitución jurídica de las entidades religiosas, la cual favorecía ampliamente a la Iglesia Católica chilena, asentando a partir de su vigencia un nuevo orden normativo basado, entre otros, en el principio rector de la igualdad jurídica de las organizaciones confesionales y en el ya destacado principio de libertad religiosa ${ }^{2}$.

\footnotetext{
1 Sobre la libertad religiosa como derecho humano, considérese Prieto Martínez, Vicente (2008). Libertad religiosa y confesiones. Bogotá: Editorial Temis/ Universidad de La Sabana, pp. 39-61. De igual modo, una acertada síntesis de las posturas que adopta la doctrina sobre el concepto de libertad religiosa, se encuentra en Palomino Lozano, Rafael (2007). Religión y Derecho comparado. Madrid: Iustel, pp. 140-150.

2 Respecto de los principios informadores del Derecho eclesiástico del Estado de Chile, considérese Salinas Araneda, Carlos (2008). "Estado no confesional y Laicismo". Revista de Derecho Universidad Católica del Norte, Vol. 1 (2008), pp. 183-202. Salinas Araneda, Carlos (2004). Lecciones de Derecho eclesiástico del Estado de Chile. Valparaíso: Ediciones Universitarias de Valparaíso, pp. 197 y ss. Asimismo, Del Picó Rubio, Jorge (2010). "La Ley de
} 
En consonancia con los propósitos señalados, la ley estableció dos caminos para obtener el reconocimiento de la personalidad jurídica de Derecho público por parte de las organizaciones religiosas, el objetivo jurídico con alcances prácticos más relevante de la reforma legal. La primera vía, de carácter general, corresponde al régimen ordinario de constitución jurídica de las entidades religiosas de Derecho público, el cual se encuentra normado en el artículo $\mathrm{N}^{\circ} 10$ de la LC, siendo aplicable a todas las agrupaciones presentes o futuras que pretendan dicho reconocimiento. La segunda vía, de alcance restringido, opera mediante el reconocimiento estatal de la preexistencia histórica de la personalidad jurídica y del ordenamiento particular originado a partir de ella, de las agrupaciones religiosas que gozaban de dicho reconocimiento en el período anterior a la dictación de la Ley $\mathrm{N}^{\circ}$ 19.638. Siendo aplicable a dos entidades religiosas ya existentes, la distinción de esta segunda vía y su consiguiente estudio, se justifica por la eventual creación de personas jurídicas derivadas ${ }^{3}$.

En ambas modalidades, la ley contempla la existencia de un sistema de constitución jurídica basada en la inclusión de las entidades en un registro público, cuya custodia ha sido encomendada al Ministerio de Justicia. Este sistema, en términos generales, adopta el ya indicado criterio de consideración de la preexistencia de la organizaciones religiosas, renunciando el legislador a toda pretensión de ponderación sustantiva del corpus de creencias de estas entidades, de modo tal que reduce la participación del órgano administrativo a una revisión más o menos compleja -según se verá más adelante- del cumplimiento de las diligencias formales de constitución legal y reglamentaria previstas.

Este trabajo aborda el problema jurídico suscitado por la objeción de la constitución de una entidad religiosa, considerando la normativa vigente y sus limitaciones al momento de enfrentar la cautela del interés público, tanto derivado del incumplimiento formal ya descrito, como del supuesto de mayor complejidad que involucra la eventual procedencia de un examen sustantivo de los antecedentes que avalan la pretensión de una entidad en formación, al afectar bienes sociales valorados por el ordenamiento jurídico.

Nuestro propósito, por tanto, es analizar el supuesto de objeción del registro de una entidad religiosa, los requisitos que para su procedencia,

Constitución jurídica de entidades religiosas: instituciones fundamentales”. En DeL PIcó Rubio, Jorge (coordinador): Derecho de la libertad de creencias. Santiago de Chile: Abeledo Perrot, pp. 7-13. Para una apreciación profundizada, véase Viladrich, Pedro-Juan 1983). "Los principios informadores del Derecho eclesiástico español". En González del VAlLe, José María et alii, Derecho eclesiástico del Estado español, Pamplona (España): Eunsa, 2a. ed., pp. 190-260.

3 Véase Del Picó Rubio, Jorge (2009). "Génesis y regulación de personas jurídicas derivadas en el marco previsto por la Ley $\mathrm{N}^{\circ}$ 19.638: efectos civiles". En Pizarro Wilson, Carlos (coordinador): Estudios de Derecho civil IV. Santiago de Chile: LegalPublishing. 
el carácter formal o sustantivo del control administrativo y los casos en que amerita su aplicación, en el marco jurídico vigente, asumiendo que la mencionada objeción determina consecuencialmente el rechazo a la constitución jurídica de la entidad, contribuyendo de este modo a aclarar una de las materias más debatidas y de mayor complejidad del sistema implantado por la LC en Chile.

\section{1) Procedimiento de CONSTITUCión JURídica de LaS ENTIDAdeS RELIGIOSAS EN EL MARCO DE LA LEY N $^{\circ} 19.638$}

El procedimiento general y ordinario de constitución jurídica de las entidades religiosas que deseen adquirir la calidad civil de personas jurídicas de Derecho público, se encuentra regulado en el artículo $10^{\circ}$ del capítulo $2^{\circ}$ de la LC, en concordancia con las disposiciones contenidas en los arts. $2^{\circ}$ y ss. del Decreto Supremo $N^{\circ} 303$. En consecuencia, toda organización de carácter religioso o agrupación de personas naturales con fines religiosos, que pretenda ser reconocida como persona jurídica de derecho público, deberá dar cumplimiento al procedimiento prescrito legalmente en dichas normas.

Dispone al efecto el art. $10^{\circ}$ de la Ley $\mathrm{N}^{\circ} 19.638$ :

"Para constituir personas jurídicas que se organicen de conformidad con esta ley, las entidades religiosas deberán seguir el procedimiento que se indica a continuación:

a) Inscripción en el registro público que llevará el Ministerio de Justicia de la escritura pública en que consten el acta de constitución y sus estatutos;

b) Transcurso del plazo de noventa días desde la fecha de inscripción en el registro, sin que el Ministerio de Justicia hubiere formulado objeción; o si, habiéndose deducido objeción, ésta hubiere sido subsanada por la entidad religiosa o rechazada por la justicia, y

c) Publicación en el Diario Oficial de un extracto del acto de constitución, que incluya el número de registro o inscripción asignado".

Por su parte, el art. $2^{\circ}$ del DS $\mathrm{N}^{\circ} 303^{4}$, en concordancia con el art. $1^{\circ}$ inc. $2^{\circ}$ del mismo reglamento, prescribe lo siguiente:

"Estas entidades [... aquellas que soliciten su registro como personas jurídicas de derecho público...] deberán constituirse por escritura pública o instrumento privado reducido a escritura pública. El instrumento privado o la escritura pública, en su caso, deberá ser firmado por todos los constituyentes, individualizados con su cédula

Reglamento para el Registro de entidades religiosas de derecho público, DS № 303. 
de identidad, y contendrá el acta de constitución, los estatutos por los cuales ha de regirse, la constancia de haber sido éstos aprobados y el poder que se confiere a la persona a quien se encarga la reducción a escritura pública del mencionado instrumento, el cual deberá contener además las facultades de solicitar el registro de la misma, y efectuar las modificaciones y cambios necesarios para subsanar las observaciones que formule el Ministerio de Justicia".

Por tanto, para erigir personas jurídicas de Derecho público, la ley exige que las entidades deberán constituirse por escritura pública o instrumento privado reducido a escritura pública, estar incorporadas en el registro público que lleva para este efecto el Ministerio de Justicia, superar satisfactoriamente la revisión de sus antecedentes formales, para que el registro quede firme, y publicar un extracto del acta de constitución en el Diario Oficial.

Para el fiel cumplimiento de las exigencias precedentes, el procedimiento aplicable consta de los siguientes pasos:

Primero, las entidades deberán constituirse mediante escritura pública o instrumento privado reducido a escritura pública, para cuyo efecto deberá haberse realizado una asamblea en la cual se haya adoptado el acuerdo constitutivo de la entidad civil;

Segundo, las entidades deberán solicitar su inscripción en el registro público de entidades religiosas al Ministerio de Justicia, acompañando una copia autorizada de la correspondiente escritura pública;

Tercero, el Ministerio de Justicia, presentada la solicitud de inscripción y antes de efectuar el registro, deberá verificar que esta contenga todas las menciones y acompañe los antecedentes exigidos por la Ley y el Reglamento;

Cuarto, el Ministerio de Justicia procederá a efectuar el registro de la entidad religiosa;

Quinto, el Ministerio de Justicia revisará dentro del plazo de noventa días, contados desde la inscripción en el registro público de entidades religiosas, el cumplimiento de los requisitos legales y reglamentarios;

Sexto, deberá haber transcurrido el plazo de noventa días, sin que el Ministerio de Justicia hubiere formulado objeciones, o subsanadas si estas se hubieren deducido o producido su rechazo por la Justicia cuando la entidad hubiere deducido la acción legal respectiva;

Véase Salinas (2004), pp. 286 y ss., y Del Picó (2010), p. 5 y ss. Para un análisis comparativo con el sistema de registro espańol, la principal referencia tenida a la vista por el legislador, considérese González del Valle, José María (2005). Derecho eclesiástico español. Madrid: Thomson Civitas, pp. 160 y ss.; López Alarcón. Mariano (2004). "Confesiones y entidades religiosas". En Ferrer Ortiz, Javier (coordinador): Derecho eclesiástico del Estado español. $5^{a}$ edición. Pamplona (España): Thomson-Civitas, pp. 177-205, pp. 196-201. 
Séptimo, la entidad religiosa deberá publicar un extracto del acta de constitución y de sus modificaciones, si las hubiere. Desde el momento de la publicación, la inscripción de la entidad quedará firme.

Octavo, desde el momento en que el registro quede firme, vale decir desde que se cumplan todos los requisitos anteriores, y en particular la publicación, la entidad religiosa gozará de personalidad jurídica de derecho público, por el solo ministerio de ley ${ }^{6}$.

Por tanto, y en lo que concierne al objeto del presente trabajo, dos son los momentos en que se contempla una revisión o control administrativo destinado a cautelar el cumplimiento de los requisitos legales y/o reglamentarios por parte de las entidades en formación. El primero, establecido en el artículo $7^{\circ}$ del DS $\mathrm{N}^{\circ} 303$, reglamento de la LC, se debe realizar antes del registro. El segundo, correspondiente a la calificación contemplada en el artículo 11 inciso $1^{\circ}$ de la LC, debe realizarse dentro del plazo de los 90 días que corren desde la fecha del registro ${ }^{7}$.

En lo que respecta a la revisión contemplada en el reglamento de la ley, esta se caracteriza por una constatación preliminar, al momento de la recepción de la solicitud de registro, de haber sido acompañados todos los antecedentes materiales requeridos para la eficaz tramitación administrativa de la solicitud ${ }^{8}$. En tal sentido, el funcionario del Ministerio revisará que el requirente acompañe toda la documentación exigida, vale decir, la solicitud dirigida al Ministro de Justicia y la copia autorizada de la correspondiente escritura pública, constando en esta el acta de constitución de la entidad religiosa y sus estatutos, debiendo tener el acta y los estatutos al menos las menciones señaladas en el art. 12 de la LC.

En los hechos, teniendo presente que las entidades han debido constituirse por escritura pública o por instrumento privado reducido a

6 Cabe señalar que ni la ley ni el reglamento exigen el patrocinio de un abogado en ninguna de estas gestiones, pese a que la naturaleza misma de los trámites requeridos y los manifiestos problemas emergentes que han afectado la correcta y oportuna tramitación de la personalidad jurídica de las entidades religiosas, así lo ha dejado en evidencia. Un grupo de trabajo técnico convocado por el Ministerio de Justicia en enero de 2002, la Comisión de estudios para la reforma de la Ley $\mathrm{N}^{\circ} 19.638$, concordó en la necesidad de incluir una nueva norma en la LC, que establezca la obligación de contar con la participación de un abogado habilitado, que patrocine la solicitud en que se pida la inscripción en el RERDP, designado con tal propósito por la asamblea constituyente de la entidad religiosa. En el mismo sentido, véase Salinas Araneda, Carlos (2001). Sectas y Derecho. Valparaíso: Ediciones Universitarias de Valparaíso, p. 292.

8 A diferencia del caso chileno, en que el control previo al registro se encuentra normado reglamentariamente, en Espańa se realiza un control previo de licitud asentado exclusivamente por la praxis administrativa. Véase al efecto, el Real Decreto 142/1981, de 9 de enero, sobre Organización y Funcionamiento del Registro de Entidades Religiosas, arts. 3-8 y sus comentarios, en Llamazares Fernández; Dionisio (2002) (director). Derecho eclesiástico del Estado. Tercera edición. Barcelona (España): Editorial Ariel, pp. 449 y 450. Asimismo, MoTiLla, Agustín (2006). "El reconocimiento estatal de las confesiones religiosas. El registro de entidades religiosas". En Álvarez Cortina, Andrés, y Rodríguez Blanco, Miguel (coordinadores): La libertad religiosa en España. Granada (España): Comares, p. 165. 
escritura pública, el funcionario verificará que dicha escritura pública o instrumento privado haya sido firmado por todos los constituyentes individualizados con su cédula de identidad, a la vez que constatará que contenga el acta de constitución, los estatutos, la constancia de la aprobación de los estatutos y el poder que se confiere a la persona a quien se encarga la reducción a escritura pública del mencionado instrumento, incluyendo asimismo las facultades para el mandatario, para solicitar el registro y efectuar las modificaciones y cambios necesarios para subsanar las eventuales observaciones que formule el Ministerio de Justicia?.

Asimismo, tras efectuar la revisión preliminar, según dispone el art. $7^{\circ}$ del Reglamento, "podrá solicitar aclaraciones, rectificaciones, enmiendas o antecedentes adicionales a los solicitantes, cuando considere que la información suministrada no es suficiente". Si bien ni la ley ni el reglamento indican un plazo para realizar esta verificación, la práctica administrativa ha determinado que, salvo excepciones, el registro se efectúa dentro de las 72 horas siguientes a la presentación de la solicitud. Por ello, las eventuales observaciones previas al registro (OPR) deberán formularse en dicho lapso ${ }^{10}$.

En cuanto a la revisión contemplada en el artículo 11 inciso primero de la LC, su propósito es velar por el cumplimiento de los requisitos legales. Su inobservancia determina que el Ministerio de Justicia puede objetar el registro ya efectuado de la entidad, el cual en tanto no concluya el plazo legal para realizar la revisión, tiene un carácter de provisional. La relevancia y complejidad de este examen motiva este trabajo, y determina su análisis detallado en los apartados siguientes

\section{2) CALIFICACIÓN DEL CUMPLIMIENTO DE LOS REQUISITOS LEGALES Y REGLAMENTARIOS, EN CONFORMIDAD AL ARTÍCULO 11 DE LA LEY $\mathrm{N}^{\circ} \mathbf{1 9 . 6 3 8}$}

Habiendo ya distinguido el examen preliminar, contemplado en el reglamento, y sus características, procede abordar en detalle la revisión administrativa contemplada en el artículo 11 de la Ley $\mathrm{N}^{\circ} 19.638$, y que tiene por objeto efectuar un control de licitud respecto de la inscripción en el registro, ya materializada con carácter provisional.

Dispone al efecto el mencionado artículo:

"El Ministerio de Justicia no podrá denegar el registro. Sin embargo, dentro del plazo de noventa días contado desde la fecha de ese acto,

\footnotetext{
$9 \quad$ Cfr. Art. $2^{\circ}$ DS 303.

10 Véase también la opinión de Carlos Salinas, muy escéptica, sobre la utilidad de las observaciones previas al registro, en Salinas (2001), p. 304.
} 
mediante resolución fundada, podrá objetar la constitución si faltare algún requisito.

La entidad religiosa afectada, dentro del plazo de sesenta días, contado desde la notificación de las objeciones, deberá subsanar los defectos de constitución o adecuar sus estatutos a las observaciones formuladas.

De la resolución que objete la constitución podrán reclamar los interesados ante cualquiera de las Cortes de Apelaciones de la región en que la entidad religiosa tuviere su domicilio, siguiendo el procedimiento y plazos establecidos para el recurso de protección".

Por tanto, la ley dispone que el Ministerio de Justicia pueda objetar la constitución de la entidad religiosa, mediante resolución fundada, cuando faltare algún requisito, disponiendo para ello del plazo de noventa días, contados desde la fecha del ingreso de la solicitud de registro. Todo ello, antes de dejar firme el registro que ha permanecido con carácter de provisional y permitir en definitiva la materialización de la constitución de la persona jurídica religiosa de Derecho público, cuando haya transcurrido el plazo legal de noventa días, sin que medie objeción, o si esta ocurrió, que los reparos hayan sido subsanados o que la objeción, reclamada por la entidad, haya sido rechazada por la Justicia.

Debe consignarse desde ya que la ley impide denegar el registro de una entidad religiosa, salvo en el caso de omisión de algún requisito, por lo que solo se podrá abortar su constitución una vez registrada, mediante el procedimiento de objeción.

Los aspectos sometidos a revisión, determinan que necesariamente se proceda al el estudio de los estatutos de la entidad y de sus documentos fundamentales, con el propósito de establecer el cumplimiento de los requisitos a los cuales alude el legislador, en principio de carácter formal, sin perjuicio, como se verá, de velar por la preservación del orden público constitucional y legal, en especial el respeto a las bases del sistema democrático de convivencia y los derechos fundamentales de las personas.

Ahora bien, ¿cuáles son los requisitos que debe cumplir la entidad requirente para que su registro no sea objetado?

Asumiendo que la suficiencia de la documentación requerida ya ha sido constatada, al igual que la inclusión de las menciones a que alude el art. $7^{\circ}$ del Reglamento, los requisitos que deben ser cumplimentados se pueden ordenar en dos categorías, a saber, los requisitos específicos exigidos por el art. 12 de la LC, en concordancia con los arts. $2^{\circ}$ a $8^{\circ}$ del Reglamento, y los requisitos generales que se derivan de la aplicación del art. $19 \mathrm{~N}^{\circ} 6^{\circ}$ inciso $1^{\circ}$ de la Constitución Política, que tutela la libertad de conciencia, la manifestación de todas las creencias y el ejercicio libre de todos los cultos que no se opongan a la moral, a las buenas costumbres o 
al orden público, restricción o marco contemplado también por remisión en el art. $1^{\circ}$ de la LC y explícitamente en el art. $1^{\circ}$ del Reglamento de la LC. Analizaremos con mayor detalle ambas categorías.

\section{a) Requisitos específicos derivados del art. 12 de la Ley $N^{\circ} 19.638$}

Dispone el art. 12 de la LC:

"En los estatutos o normas propias de cada persona jurídica que se constituya en conformidad a las disposiciones de esta ley deberán contenerse aquellos elementos esenciales que la caracterizan y los órganos a través de los cuales actúa en el ámbito jurídico y que la representan frente a terceros.

El acta constitutiva contendrá, como minimo, la individualización de los constituyentes, el nombre de la persona jurídica, sus domicilios y la constancia de haberse aprobado los estatutos.

Las personas condenadas por delito que merezca pena aflictiva no podrán suscribir el acta de constitución de la persona jurídica".

Analizaremos brevemente los requisitos legales, concordados con las normas reglamentarias, distinguiendo aquellos aplicables al acta de constitución y los propiamente aplicables a los estatutos de la entidad.

Respecto de los requisitos del acta constitutiva, la ley dispone que ella contenga, como mínimo, la individualización de los constituyentes, el nombre de la persona jurídica, sus domicilios y la constancia de haberse aprobado los estatutos. El acta no podrá ser suscrita por personas condenadas por delitos que merezca pena aflictiva, aunque nada impide que, con posterioridad a este acto, pertenezcan formalmente a ella.

Respecto de los estatutos, la ley dispone que cada persona jurídica que se constituya en conformidad a sus normas, deba contener en ellos los elementos esenciales que la caracterizan y los órganos a través de los cuales actúa en el ámbito jurídico y que la representen frente a terceros. Dicha indicación es detallada y aumentada posteriormente en el art. $6^{\circ}$ del Reglamento, la que debe complementarse con lo dispuesto en el art. $5^{\circ}$ del mismo texto normativo, que prescribe la obligación de disposición de los estatutos y documentos fundamentales de la entidad religiosa en su domicilio principal, para facilitar el libre acceso a la información contenida en ellos.

El art. $6^{\circ}$ prescribe que los estatutos de toda entidad religiosa, cuya personalidad jurídica se constituya en conformidad a la Ley $\mathrm{N}^{\circ} 19.638$, deberán contener, a lo menos, la indicación precisa del nombre y domicilio principal de la entidad, y los otros domicilios que pudiere tener; los elementos esenciales que la caracterizan y los fundamentos y principios en que se sustenta la fe que ella profesa; los órganos de administración, 
sus atribuciones y el sistema o forma de elección o designación de sus integrantes y el número de miembros que los componen, como asimismo el cargo al cual se atribuye la representación judicial y extrajudicial de la persona jurídica; las normas internas que establezcan los requisitos de validez para la adquisición y enajenación de sus bienes y la administración de su patrimonio; las disposiciones que regulen el acuerdo de reforma de sus estatutos y de disolución de la entidad, indicándose la institución a la cual pasarán sus bienes en este último evento, la que bajo ningún respecto podrá perseguir fines de lucro ni dichos bienes pasar al dominio de alguno de sus integrantes; la forma de ingreso, permanencia y abandono de la entidad religiosa, especificando los requisitos correspondientes a dichos actos, debiendo los estatutos asegurar el libre y voluntario acceso, cambio o abandono de la entidad religiosa, pudiendo los incapaces incorporarse a la entidad religiosa ejerciendo sus derechos en conformidad a la ley. Nos detendremos para analizar someramente aquellos requisitos de mayor relevancia para el propósito de este trabajo.

Respecto de la denominación de la entidad, procede efectuar un examen que permita detectar posibles repeticiones en su utilización, ya sea porque esta habría sido ya registrada por otra agrupación en forma precedente, usando los mismos términos, o porque se produce una réplica evidente de los datos que configuran la identidad de una entidad, incluyendo aquí la identidad del corpus de creencias, de su doctrina, ritos, símbolos y estructura organizativa, además del uso parcial de la denominación de otra entidad, de modo tal que se induzca a confusión tanto a sus adherentes como a los terceros que se relacionen con ella. La denominación de la entidad se vincula a la identidad legal e histórica de una determinada confesión religiosa, configurando un problema que presenta al menos dos aristas principales, referidas por una parte a la eventual pérdida de dicha identidad como consecuencia de la pretensión exitosa de una agrupación sobre un nombre que cuenta con arraigo y posee significación histórica ${ }^{11} \mathrm{y}$, por la otra, en la necesaria consideración de la distinción que es necesario efectuar entre los términos de uso universal y aquellos que son susceptibles de apropiación y que, por tanto, pueden aspirar a ser protegidos por el Derecho. Sobre la materia y en particular

11 Respecto del punto, Lagos señala que la ley adolece de una omisión que no puede resolverse adecuadamente por la vía reglamentaria, consistente en el hecho que "las entidades actualmente con vida jurídica (de derecho privado y/o derecho público), pueden perder su identidad legal e histórica, si en función de la nueva ley algún grupo se les anticipe y reclame para sí un nombre específico, que pudiere, por ejemplo, ser el mismo de una que hoy lo tenga en tanto que persona de derecho privado sin fin de lucro". Lagos Schupfeneger, Humberto (2010). "La ley de constitución jurídica de entidades religiosas: antecedentes históricos y análisis normativo desde la perspectiva de las confesiones minoritarias". En Del Picó Rubio, Jorge (coordinador): Derecho de la Libertad de creencias. Santiago de Chile: Abeledo Perrot, pp. 39-46, p. 42. 
respecto del examen tendiente a establecer la semejanza de nombre entre la entidad que solicita el registro y otra que ya estuviere registrada con el mismo nombre, cabe establecer algunas precisiones. Primero, que debe discutirse la procedencia del uso del término corporación, el que en propiedad corresponde a la denominación genérica de las personas jurídicas constituidas a partir de la voluntad asociativa de una agrupación de personas, que persiguen un fin socialmente valorado y que se caracterizan por no tener un propósito de obtención de lucro ${ }^{12}$. En segundo término, algunas palabras de significación religiosa son de dominio universal, no pudiendo ser apropiadas, como ocurre con los términos "cristianismo", "evangélico", "pentecostal" y "budista", por citar algunos ejemplos. En tercer término, no podrán registrarse las entidades religiosas cuyo nombre completo sea igual o tenga notoria similitud gráfica y fonética al de otra legalmente existente en el territorio nacional, a menos que esta la autorice expresamente mediante escritura pública ${ }^{13}$. La norma alude a una similitud formal, como ocurre cuando los términos utilizados para conformar el nombre de una entidad es similar al de otra, sin perjuicio de lo cual estimamos que el examen también debe comprender la pretensión de asimilación de una entidad en formación con otra, cuando replica todas las denominaciones propias de aquella que ya se encuentra debidamente registrada, de modo tal que induce a confusión a quienes se relacionan con ella ${ }^{14}$.

La referencia a los elementos esenciales que caracterizan a la entidad, prescrita en el inciso primero del artículo 12 de la LC, alude fundamentalmente al corpus de creencias de la agrupación religiosa, y que configuran al grupo como religioso, debiendo comprender a lo menos una descripción mínima pero suficiente, del credo religioso o expresión de fe fundamental en torno a la existencia de un Ser superior, trascendente o no, al cual adhieren las personas que solicitan el registro; sus dogmas de fe o conjunto de verdades doctrinales; una indicación precisa de los actos

12 El legislador tuvo la intención de diferenciar a las organizaciones que persiguen finalidades religiosas y de culto, distinguiéndolas positivamente y evitando su asimilación a las personas jurídicas de derecho privado que, no teniendo carácter lucrativo, persiguen el cumplimiento de otras finalidades. Esta fue, además, una de las demandas históricas de las organizaciones ligadas a las confesiones minoritarias, especialmente las evangélicas. La persistencia en su uso por parte de algunas entidades, generalmente adscritas a la denominación pentecostal, responde a una tradición enmarcada en una norma cuyo uso para ordenar jurídicamente las agrupaciones religiosas ya no se justifica, al existir la actual normativa, de mayor pertinencia, utilidad y alcance, contribuyendo la persistencia de su utilización más bien a sembrar confusión entre quienes interactúan con estas entidades. Lo correcto, particularmente en el caso indicado, es recurrir a la denominación "iglesia", y en otros casos no cristianos, a denominaciones como comunidad, congregación, misión o derechamente entidad religiosa.

13 Véase art. $8^{\circ}$ del DS $\mathrm{N}^{\circ} 303$.

14 Véase el planteamiento del problema de la denominación y otros elementos identificatorios en el derecho español, en Motilla (2006), pp. 158-159. 
de carácter ritual, tanto individuales como colectivos que configuran el culto religioso; la existencia o no de alguna vinculación o derivación de las grandes religiones existentes; la estructura eclesial o de organización interna de la entidad y la indicación fundada del nombre con el cual será conocida $^{15}$. La materia se relaciona necesariamente con el problema de la apreciación de los fines religiosos declarados por la entidad, materia que profundizaremos en el apartado siguiente.

En cuanto a las normas que regulan la forma de ingreso, permanencia $y$ abandono de la entidad religiosa, cuya inclusión explícita reconoce origen en el propósito del legislador en orden a precaver cualquier actividad sectaria peligrosa, corresponde señalar que, en primer lugar, deberá observarse con acuciosidad el modo en que los estatutos consagran la libertad de los individuos para acceder y retirarse de la entidad, sin forma alguna de coacción. En la materia, reviste especial relevancia el modo en que se contempla la incorporación de menores de edad, salvaguardando en todo momento el derecho que asiste a los padres y tutores para autorizar su ingreso en estas organizaciones, en conformidad a la legislación vigente. En especial, deberá establecerse con claridad el derecho de abandonar la organización y, si así lo estima la persona, adherir a otra religión, sin posibilidad de coacción alguna por parte de la entidad en orden a retener su membresía o adhesión ${ }^{16}$. Cabe destacar el reforzamiento del criterio legislativo sobre la materia apreciada en la reciente normativa legal sobre asociaciones, la cual reitera que nadie puede ser obligado a constituir una asociación, ni a integrarse o a permanecer en ella, concluyendo en declarar que el acto de afiliación es libre, personal y voluntario ${ }^{17}$.

El artículo $5^{\circ}$ del Reglamento contempla la obligación para los miembros de la entidad religiosa, de disponer los estatutos y documentos fundamentales de la entidad religiosa en su domicilio principal, para facilitar el libre acceso a la información contenida en ellos por parte de quien así lo solicite. Respecto de los documentos fundamentales, la práctica del Ministerio de Justicia ha establecido que se consideren como tales -además de los estatutos- los libros, folletos o textos en los cuales se incluya el

15 Considérese al respecto, Motilla (2006), p. 162.

16 Por tanto, no podrá incluirse norma alguna que establezca requisitos para abandonar la entidad, salvo aquellas que cautelen el interés patrimonial de esta, como en el caso del servicio de deudas impagas o la devolución de bienes comunes entregados al ex miembro para el mejor cumplimiento de los fines de la entidad religiosa, como ocurriría por ejemplo con la obligación de dar cuenta de la administración de un inmueble o el uso de un vehículo motorizado.

17 Confróntese con el artículo $3^{\circ}$, inc. $1^{\circ}$, Ley $\mathrm{N}^{\circ}$ 20.500. Asimismo, el inc. $2^{\circ}$ del citado artículo enfatiza el principio de libertad asociativa, disponiendo: "Ni la ley ni autoridad pública alguna podrán exigir la afiliación a una determinada asociación, como requisito para desarrollar una actividad o trabajo, ni la desafiliación para permanecer en éstos". 
cuerpo de creencias religiosas de la entidad y su doctrina, los nombres de quienes la dirigen y los requisitos establecidos para el ingreso y el retiro de los integrantes de la entidad. El acceso libre de los terceros interesados en conocer dichos documentos y su contenido, se entiende restringido al domicilio principal, en días y horas hábiles, y en las oficinas dispuestas para tal efecto. No se debe entender incluido en esta facultad amplia, el acceso irrestricto de terceros a los templos ni a otras dependencias del recinto principal consagrados al culto religioso o a la práctica del rito religioso por parte de los fieles de la confesión sometida a la exigencia de escrutinio. El acceso de la autoridad o de otras personas, en este último caso, está sometido a las normas generales que regulan el acceso a recintos de dominio privado.

\section{b. Requisitos generales de conformidad de la entidad religiosa con el ordenamiento jurídico vigente.}

Junto con cumplimentar los requisitos legales y reglamentarios específicos, ya abordados en el apartado precedente, la entidad en formación deberá cumplir con las exigencias generales del ordenamiento constitucional y legal, comunes a toda persona jurídica o a la categoría particular en que ella se incluye, derivadas de la naturaleza corporativa de la entidad. Debe, por tanto, distinguirse dos concordancias con el ordenamiento jurídico general.

En primer lugar, debe establecerse la necesaria concordancia derivada de la naturaleza corporativa de la entidad y de su especificidad religiosa, debiendo incluir los estatutos el señalamiento explícito de fines propios de carácter religioso, descartándose por tanto toda finalidad política, gremial, académica o de beneficencia, por citar algunos ejemplos recurrentes.

La apreciación de los fines religiosos constituye uno de los problemas medulares del proceso de calificación de los antecedentes aportados por los requirentes del registro, dando forma también a uno de los temas de mayor complejidad en lo que a reconocimiento estatal de las organizaciones religiosas se refiere.

El problema remite a dos cuestiones enlazadas entre sí, constituyendo la primera el antecedente necesario para fijar el alcance de la segunda. En efecto, corresponde en primer lugar determinar el concepto de religión que servirá de base y referencia para establecer coherentemente lo que se entenderá por fines religiosos. No existiendo una definición legal de religión, corresponde recurrir a la que brinda la Real Academia Española de la Lengua, la cual expresa el concepto en los siguientes términos: "Un conjunto de creencias o dogmas acerca de la divinidad, de sentimientos de temor y veneración hacia ella, de normas morales para la conducta individual y social y de prácticas rituales, principalmente la oración y 
el sacrificio para darle culto"18. A partir de ella, se coligen los fines que apuntan a la satisfacción del sentido acogido por la definición, a saber, que el objetivo de la entidad es agrupar a las personas que participan en unas mismas creencias sobre la divinidad, para considerar en común esa doctrina, orar y predicar sobre ella, realizar los actos de culto que sus sistema de creencias establece y promover la realización de una conducta comunitaria y social concordante con los principios orientadores basados en dicho sistema de creencias ${ }^{19}$.

Ahora bien, ¿es suficiente la mera declaración formulada por la entidad en orden a tener fines religiosos o incluso de indicarlos en la especie, para dar por satisfecho el requisito legal? La pregunta enfoca el punto central del debate, respecto del cual no existe acuerdo en la doctrina nacional ni comparada, como se puede apreciar con ocasión del controvertido fallo sobre la denegación del registro de la Iglesia de Unificación, tanto en Chile como en España, su antecedente directo. Por lo pronto, adelantamos nuestra opinión, inscrita en la corriente de considerar como ineludible el pronunciamiento primario de la Administración, en presencia de una solicitud expuesta por una organización evidentemente no religiosa, como por ejemplo un emprendimiento de educación superior o una asociación terapéutica. Asimismo, cuando se advierta una evidente colisión entre los fines religiosos declarados por la entidad y el ordenamiento jurídico nacional, particularmente el respeto de los derechos fundamentales de las personas.

El carácter o finalidad lucrativa debe descartarse en términos absolutos, tanto respecto de las entidades religiosas como de las personas jurídicas que ellas constituyan, en conformidad a lo dispuesto por el art. $9^{\circ}$ inc. $2^{\circ}$ de la LC, norma redundante si se tiene en consideración la naturaleza corporativa de la entidad, no pudiendo contener menciones explícitas ni tampoco desprenderse implícitamente, como por ejemplo a partir de la apreciación de las actividades que realice la entidad matriz o las personas derivadas, aun bajo el predicamento justificativo de contribuir a la mantención financiera de la organización religiosa. Esto último se extiende al examen de la gestión de las personas jurídicas derivadas y, en especial, a la actividad que realicen como entidades "espejo" las personas jurídicas de derecho privado que, por decisión de sus miembros, aún subsistiere en forma paralela a la persona jurídica de derecho público.

Asimismo, debe necesariamente descartarse el carácter gremial de la entidad requirente de registro, interpretación que puede colegirse con claridad del art. $4^{\circ}$ de la LC, que en lo pertinente entiende por iglesias, con-

18 Real Academia Española (1992). Diccionario de la lengua española. Vigésima primera edición. Madrid (España): Espasa-Calpe, p. 1250.

19 En el punto, nos remitimos al concepto utilizado por el Tribunal Constitucional espańol, recogido en Motilla (2006), p. 163. 
fesiones o instituciones religiosas, a las entidades integradas por personas naturales que profesen una determinada fe. El texto, como se aprecia, no incluye a las entidades integradas por personas jurídicas ${ }^{20}$.

En segundo lugar, aplican las exigidas por la debida concordancia con el ordenamiento constitucional, en particular las restricciones derivadas de la moral, el orden público y las buenas costumbres. Procede cautelar que las normas y elementos esenciales contenidos en los documentos fundamentales de la entidad, no se opongan a la moral, las buenas costumbres o al orden público, en concordancia con lo dispuesto por el art. 19 No 6 de la CPE y el art. $1^{\circ}$, inc. $1^{\circ}$ del DS 303 . Con base en este marco, procede efectuar un análisis en profundidad respecto de la veracidad del carácter confesional y de la prosecución de fines religiosos por parte de la entidad cuyo reconocimiento público se pretende. Analizaremos con mayor detención el punto en el apartado siguiente.

\section{3) CALIFICACIÓN FORMAL O SUSTANTIVA DE LOS REQUISITOS EXIGI- DOS PARA EL REGISTRO. INCIDENCIA EN EL CARÁCTER FORMAL O SUSTANTIVO DE LA OBJECIÓN ADMINISTRATIVA}

El examen de los antecedentes o trámite calificador, especialmente a partir de la experiencia española, ha sido considerado profusamente en la doctrina comparada, la que en general es coincidente en la necesidad de la existencia un examen que considere tanto los aspectos estrictamente formales de la presentación de la solicitud de registro como la determinación del carácter religioso de los fines declarados por la entidad en formación, aunque reconociendo también el riesgo de que "la Administración estatal pueda restringir indebidamente el ejercicio del derecho de libertad religiosa" 21 . Así, en el caso español, existen antecedentes de pronunciamientos del Tribunal Supremo (TS) que, en un caso, valida la función calificadora ejercida por la Administración y delimita su alcance a la constatación de los aspectos formales encaminados a garantizar su individualización ${ }^{22}$, pero también otro que deniega la inscripción de una entidad religiosa por estimar que su doctrina y fines no son religiosos ${ }^{23}$. Sin perjuicio de lo anterior, al igual que lo acontecido posteriormente en Chile,

20 Confróntese con los artículos $4^{\circ} \mathrm{LC}$ y $6^{\circ}$ DS 110.

21 López Alarcón, Mariano (2004). "Confesiones y entidades religiosas". En Ferrer Ortiz, Javier (coordinador): Derecho eclesiástico del Estado español. $5^{a}$ edición. Pamplona (España): EUNSA, p. 198; GonZález del Valle, José María (2005). Derecho eclesiástico español. $6^{a}$ edición. Cizur Menor (España): Thomson / Civitas, p. 161.

22 Sentencia del Tribunal Supremo español de 2 de noviembre de 1987, que admitió el registro de la Iglesia Cristiana Palmariana de los Carmelitas de la Santa Faz.

23 Sentencia del Tribunal Supremo español de 25 de junio de 1990, que denegó el registro de la Iglesia Cienciológica de España. 
el caso de mayor complejidad, tanto por la naturaleza de la entidad cuestionada como por el pronunciamiento en superior instancia y que quebró la línea jurisprudencial seguida por el TS, corresponde a la solicitud de registro de la Iglesia de la Unificación, denegada en primera instancia por el TS y aceptada con posterioridad por el Tribunal Constitucional el 15 de febrero de 2001, sobre la base de negar al encargado del Registro de Entidades Religiosas la facultad calificadora, para reconocerle solamente una función de constatación de datos ${ }^{24}$.

Volviendo al análisis de la objeción contemplada en la LC, ya se ha adelantado que el legislador no concedió a la autoridad administrativa la facultad de denegar el registro, razón por la cual, tras efectuar una revisión formal, el Ministerio de Justicia deberá proceder al registro solicitado. Por tanto, ante la eventual advertencia de un caso de transgresión normativa, no procede denegar el registro, sino esperar el momento de la calificación o examen, contemplado en el art. 12 de la LC, para objetar el registro si concurrieren los requisitos para ello.

El fundamento de esta interpretación se encuentra en la historia de la ley, particularmente en el debate sostenido en el seno de la Comisión de Constitución, Legislación y Justicia de la Cámara, en donde primó la posición de limitar o restringir el papel fiscalizador del Estado a la salvaguardia del "justo orden público" 25 , concepto dentro del cual se incluyó la moral y las buenas costumbres.

Se justificó lo anterior en la necesidad de evitar asentar precedentes de intervención administrativa o estatal más allá de los límites legítimos que, a juicio de los comisionados, reconoce el Derecho moderno ${ }^{26}$. En los hechos, durante la discusión parlamentaria del proyecto de Ley de cultos, se tuvo en vista, recurrentemente, la posibilidad de proceder a una distinción cualitativa entre distintos credos, con el propósito de precaver la existencia legal de sectas religiosas peligrosas. Sin embargo, al menos al iniciarse la tramitación de la LC, el tema en cuestión no era este, sino más bien la necesidad de diferenciar cultos religiosos y confesiones integradas por grupos minoritarios de la sociedad, de aquellas que contaban con un

\footnotetext{
24 López (2004), p. 199.
}

25 Véase Frei Toledo, Jorge y Quintana, Augusto (2001). "Aspectos relevantes de la tramitación parlamentaria”. En Del Picó Rubio, Jorge (coordinador). Ley de cultos y documentos complementarios. Santiago de Chile: KAS/ ICHEH, p. 53

26 Frei y Quintana (2001), p. 53. Asimismo, considérese las posiciones contrapuestas del senador Ríos y de Jorge Precht, en Precht Pizarro, Jorge (1998). Un caso de mutación legislativa, la ley de iglesias. Santiago de Chile: Instituto Chileno de Estudios Humanísticos, pp. 21 y ss. En particular, el senador Ríos promovió la supresión de la norma originalmente propuesta, que contemplaba controles sustantivos, consignándose en el primer Informe del Senado que la vigencia de la señalada norma, habría abierto un campo para la intervención de los funcionarios administrativos, que podrían por esta vía decidir qué grupos serán autorizados para constituirse como personas jurídicas". 
mayor número de adeptos, además de una fuerte presencia social, política y cultural, en particular la Iglesia Católica. Expuesta la situación de este modo, quedaba en evidencia entonces la necesidad de determinar a quién correspondería, en teoría, discriminar entre unas y otras entidades, para establecer, por ejemplo, el criterio del mayor arraigo de una iglesia en el país, al tenor del precedente legal español.

En presencia de un problema insoluble, con grandes suspicacias y temores manifestados por los representantes de las comunidades religiosas minoritarias, los legisladores optaron por desechar los exámenes de fondo o sustantivos, referidos al cuerpo central de creencias compartidas por los requirentes, y mantener solo los referidos a los aspectos formales mínimos. La discusión fue zanjada en términos de eliminar los controles administrativos por parte del Ministerio de Justicia -que sujetaría a las nuevas entidades a una pervivencia de los controles dispuestos por el DS 110-y, a la vez, no incluir normas que facultaran a la autoridad administrativa para efectuar investigaciones conducentes a la valoración sustantiva del régimen de creencias de la entidad y de sus propósitos religiosos. Esta posición se materializó en la enmienda introducida por la Comisión presidida por el senador Ríos, que rechazó el inciso segundo del primitivo art. $8^{\circ}$ del proyecto de ley original, que consagraba la exclusión de entidades y actividades relacionadas con el estudio y experimentación de fenómenos psíquicos así como de otras calificadas como ajenas o diferentes al conocimiento y culto religioso. El inciso tercero, que prohibía la existencia de entidades o el desarrollo de actividades destinadas al satanismo, también sería suprimido, en la Comisión Especial del Senado, por sustentarse esta distinción en una previa aceptación de una determinada concepción reli$\operatorname{giosa}^{27}$.

Esta perspectiva, confrontada con otras posiciones en las siguientes instancias de la tramitación legislativa, terminó por imponerse y determinar, en definitiva, el sentido prescriptivo de la LC.

Si bien la opción elegida, a nuestro juicio, fue la correcta, no es menos cierto que se incurrió en un lamentable error, al no establecer en términos explícitos un examen de la naturaleza y propósito religioso de la entidad, que permitiera precaver actos de organizaciones que simularan perseguir un objetivo religioso, para así utilizar las facilidades de constitución jurídica brindadas por la Ley de cultos y ahorrarse, en consecuencia, los trámites mayores exigidos para otro tipo de personas jurídica o, derechamente, para construir plataformas corporativas de apariencia religiosa que sirvieran para cometer actos ilícitos ${ }^{28}$.

\footnotetext{
27 Véase Frei y Quintana (2001), cit., nota 14. Asimismo, considérese las prevenciones formuladas al respecto por Carlos Salinas, en SaLinas (2001), p. 299.

28 Considérese la apreciación de Salinas sobre las sectas religiosas peligrosas y la LC, en SALInas Araneda (2001). Sectas y Derecho. Valparaíso: Ediciones Universitarias de Valparaíso, $417 \mathrm{pp}$.
} 
Sin perjuicio de lo anterior, y considerando precisamente el contexto histórico en que se produjo la discusión de la Ley de cultos, la norma debe ser correctamente interpretada. Esto, por cuanto más que la necesaria prevención de actos irregulares, el propósito principal de la iniciativa era brindar un estatuto igualitario a las confesiones religiosas minoritarias, y cualquier aumento de los requisitos habría de ser interpretado como un obstáculo interesado al avance de la normativa que, según sus impulsores, consagraría la libertad religiosa en Chile.

En definitiva, la correcta interpretación de las normas sobre calificación del registro, determina que el Ministerio de Justicia debe ejercer una función calificadora que garantice no solo el cumplimiento por parte de la entidad requirente de los requisitos legales estrictamente formales, sino también el debido cumplimiento de las normas fundamentales del ordenamiento en un sentido material, lo cual remite a la observancia del orden público, la moral y las buenas costumbres, y que la entidad y los fines declarados posean efectivamente un carácter religioso ${ }^{29}$.

En relación con lo dicho, cabe enfatizar que uno de los pilares sobre los cuales se ha erigido la regulación de las entidades religiosas en Chile, lo constituye la ausencia de los denominados controles sustantivos en el proceso de creación de la entidad religiosa como persona jurídica de Derecho público. En efecto, el legislador optó por entender que compete al Estado velar, solamente, por el cumplimiento de requisitos de forma exigidos a la entidad, sin posibilidad alguna de entrar a ponderar la mayor o menor bondad de los elementos fundamentales de la fe o credo religioso, que profesa el grupo de personas que ha presentado la solicitud de reconocimiento. La correcta comprensión del principio involucrado es crucial para entender el sentido del cuerpo normativo en su conjunto, por cuanto si bien en el Derecho comparado existen varias formas para establecer la relación jurídica entre las entidades religiosas y el Estado, el sistema adoptado por el legislador chileno se caracteriza por el valor asignado al principio de neutralidad en la consideración que debe prestar el Estado a las diferentes confesiones religiosas, lo que se refleja en la prescindencia del juicio estatal sobre las diferentes religiones y la preeminencia de la autonomía organizacional en un plano de igualdad jurídica tutelada por la ley.

Ahora bien, sin perjuicio de la imposibilidad absoluta de efectuar valoraciones subjetivas por parte de los agentes estatales sobre los elementos esenciales del corpus de creencias y de la doctrina asumida por la entidad religiosa, es legalmente factible $y$, a nuestro juicio, imprescindible, ponde-

Véase los comentarios sobre la materia de Lagos Schuffeneger (2010) 42 y 43; y Salinas Araneda, Carlos (2009). "El Derecho eclesiástico del Estado de Chile al tiempo del Bicentenario: logros y dificultades". Revista de Derecho de la Pontificia Universidad Católica de Valparaiso. $\mathrm{N}^{\circ} 33$, pp. 499-533, p. 505. Asimismo, Salinas (2001), pp. 295-303. 
rar el mérito religioso de la entidad -que se trate efectivamente de entidades religiosas que persiguen fines de esta naturaleza ${ }^{30}-\mathrm{y}$ analizar la correspondencia de dichos fines con el orden público, pudiendo en todos estos supuestos, objetar el registro ya efectuado, fundando dicha decisión en el respeto al ordenamiento constitucional del Estado, en observancia de la limitación establecida en el artículo $19 \mathrm{~N}^{\circ} 6^{\circ}$ de la Constitución política, que impone como requisito básico el respeto al orden público, la moral y las buenas costumbres ${ }^{31}$.

Por tanto, en esta línea de aplicación interpretativa, las actividades o conductas que se pretende desarrollar por la entidad religiosa, no deberán afectar el derecho de las demás personas al ejercicio de sus libertades y derechos fundamentales, ni ser contrarias a la seguridad, salud o moralidad pública, como elementos en que se traduce el orden público ${ }^{32}$. Se trata, en definitiva, de la aplicación de un límite constitucional explícito al ejercicio del derecho a la libertad religiosa, que surge directamente del art. 19 $\mathrm{N}^{\circ} 6$ de la Carta Fundamental ${ }^{33}$, en plena concordancia con lo dispuesto por el art. 12 numeral $3^{\circ}$ de la Convención Americana de Derechos Humanos, el cual dispone: "La libertad de manifestar la propia religión y las propias creencias está sujeta únicamente a las limitaciones prescritas por la ley y que sean necesarias para proteger la seguridad, el orden, la salud o la moral públicos o los derechos o libertades de los demás" 34 .

30 Una de las funciones derivadas de la noción de persona jurídica aplicada a las entidades religiosas, es precisamente la de excluir de su régimen jurídico a aquellas otras personas jurídicas que no desarrollan actividades religiosas. Véase González Del Valle (2005), p. 161. Cabe consignar que, finalmente, la Comisión de estudios constituida por el Ministro Gómez para analizar eventuales reformas que perfeccionaran la LC, concordó en conferir al Ministerio de Justicia, "a través de su departamento especializado, la atribución para velar por el cumplimiento de las normas establecidas en la ley". La atribución indicada, "comprende la inclusión entre las normas de la Ley $\mathrm{N}^{\circ} 19.638$ y de su reglamento, de procedimientos que procuren conferir la calidad de personas jurídicas de derecho público solo a entidades religiosas y no a otras, sin calificar la mayor o menor bondad de los propósitos fundacionales del grupo que solicita el reconocimiento". Véase Ministerio de Justicia (2002). Informe de la Comisión de Estudios para establecer proposiciones de modificación de las normas de la Ley $N^{\circ} 19.638$ y su Reglamento. Santiago de Chile: inédito, p. 3. Asimismo, SALINAS (2001), p. 294.

32 Véase Frei y Quintana (2001), cit., p. 53. Siguiendo a Cea, "el legislador siempre será llamado, por exigencias de bien común, a legislar en lo que son los principios abiertos -la moral, las buenas costumbres y el orden público- para los efectos de concretarlos desde el ángulo penal, o sea, sancionar las transgresiones a ellos, como en el caso de las sectas llamadas destructivas". Cea Egaña, José Luis (1998). Mérito constitucional del proyecto de ley sobre organizaciones religiosas. Santiago de Chile: Instituto Chileno de Estudios Humanísticos, p. 47.

33 Nogueira Alcalá, Humberto (2008). Derechos fundamentales y Garantías Constitucionales. Santiago de Chile: Librotecnia, p. 24.

34 Véase Decreto $\mathrm{N}^{\circ} 873$, de 5 de enero de 1991, que aprueba la Convención Americana sobre Derechos Humanos, denominada "Pacto de San José de Costa Rica", en el Apéndice de la Constitución Politica de la República, Decimocuarta edición, 2010. Santiago de Chile: Editorial Jurídica de Chile, p. 623. Véase también Gros Esprell, Héctor (1991). La Convención 
Las limitaciones al ejercicio del derecho de libertad de manifestación de creencias, consagrada en el art. $18 \mathrm{~N}^{\circ} 3$ del Pacto Internacional de Derechos Civiles y Políticos, también son contempladas por el Comité de Derechos Humanos de Naciones Unidas, la que en todo caso remarca el carácter estricto de la interpretación que avala su aplicación ${ }^{35}$.

\section{4) CORRESPONDENCIA DE LOS FINES RELIGIOSOS Y LA NOCIÓN DE ORDEN PÚBLICO IMPERANTE}

La noción de orden público admite un significado en extremo variable según cual fuere la perspectiva que origina la necesidad de su utilización. En general, y siguiendo una tendencia de consideración de mínimos, alude al estado de convivencia pacífica en que, con seguridad, se ejercen los derechos. Avanzando en una lectura constitucional, el orden público se define como "el conjunto de condiciones que aseguran el funcionamiento armónico y normal de las instituciones sobre un sistema de valores y principios jurídicos dentro de un Estado Constitucional Democrático" 36 . Concretándolo en la perspectiva del Derecho eclesiástico del Estado, y siguiendo en ello lo dispuesto en el art. 3 número 1 de la Ley Orgánica de Libertad Religiosa de España (LOLR), se concibe el orden público como "la protección del derecho de los demás al ejercicio de sus libertades públicas y derechos fundamentales, asi como la salvaguardia de la seguridad, de la salud y de la moralidad pública" 37.

Desde la doctrina constitucional alemana, es interesante consignar la distinción que, con ocasión de dudas ciudadanas surgidas con ocasión de la indeterminabilidad de los presupuestos para la intervención a criterio de las autoridades administrativas, ha realizado el Tribunal Constitucional Federal alemán. En la Sentencia de la Sala Primera de 14 de mayo de 1985, con ocasión de la revisión de los límites del derecho fundamental a reunión, distinguió entre seguridad pública y orden público. Se entiende que la noción de seguridad pública comprende "la protección de los bienes jurídicos centrales como la vida, la salud, la libertad, la honra, la propiedad, y el patrimonio del individuo, así como la integridad del ordenamiento legal y de los establecimientos estatales, en donde se entiende que hay una amenaza en contra de la seguridad pública cuando existe la amenaza de una violación de esos bienes jurídicos, sancionable penal-

Americana y la Convención Europea de Derechos Humanos. Análisis comparativo. Santiago de Chile: Editorial Jurídica de Chile, p. 84.

35 Nogueira (2008), p. 25.

36 Nogueira (2008), pp. 25-26.

37 Fornés, Juan et alii, (2006). Legislación eclesiástica. 8a. edición. Cizur Menor (España): Aranzadi, p. 119. 
mente". Por su parte, bajo el concepto de orden público, "se entienden la totalidad de las reglas no escritas, cuya observación, de acuerdo con las respectivas concepciones sociales y éticas predominantes, se ve como presupuesto indispensable de una ordenada convivencia humana al interior de un territorio determinado" 38 .

Considerando lo anteriormente expuesto, para los efectos buscados en este trabajo, la noción de orden público puede ser abordada a lo menos en tres dimensiones.

En la primera mirada, la noción de orden público se traduce en la exigencia de armonía normativa con el ordenamiento constitucional y, particularmente, con las bases de la institucionalidad, además de las normas legales de Derecho público y las de derecho privado no disponibles. En aplicación de esta perspectiva, las normas propias de la entidad religiosa, ya sean las indicadas en los documentos fundacionales o en documentos posteriores amparadas por el principio de autonomía reconocido por la Ley 19.638, deben guardar la debida coherencia con el conjunto del ordenamiento jurídico chileno, entre las cuales se incluyen por recepción los tratados internacionales ratificados por Chile. Esta acepción, coincidente con la noción de seguridad pública en la doctrina alemana antes vista y con aquella dispuesta en la LOLR española, es la que en nuestra opinión cabe aplicar con ocasión de la calificación de la entidad en formación, abarcando aspectos en apariencia tan disímiles como el respeto al pluralismo político, la seguridad y la salud pública ${ }^{39}$.

Una segunda mirada, de carácter jurídico más discutible y en proceso de desarrollo en la doctrina, conlleva que se debe incluir dentro de la noción de orden público la obligación de promoción y defensa de los derechos fundamentales, como una derivación del implícito principio de colaboración recíproca entre el Estado y las entidades religiosas. Sobre esta base, vale decir, el principio de colaboración, se debe entender la concesión de las facultades de exención tributaria y de autonomía normativa eclesiástica, por parte del Estado chileno a las entidades religiosas, que exigen como contrapartida una colaboración activa de las entidades religiosas con la sociedad política que les brinda tan especial y relevante reconocimiento. Si bien la lectura es sustantivamente correcta, esta perspectiva es difícilmente aceptable en una etapa de desarrollo tan incipiente de las relaciones de colaboración entre Estado e Iglesia, particularmente atendiendo la historia de nuestro país en la materia ${ }^{40}$.

38 Schwabe, Jürgen (2003). Cincuenta años de Jurisprudencia del Tribunal Constitucional alemán. Traducción de Anzola, Marcela. Montevideo: Konrad Adenauer Stiftung, p. 196.

39 Véase también Salinas (2001), pp. 294-295.

40 Según Calvo, el contenido y sentido actual del concepto de orden público, lo aleja de una justificación en servicio del Estado y lo radica, con fuerza, en normas que se entienden al 
Una tercera mirada considera como orden público al estado de ordenada convivencia en un territorio determinado, en el que se prodiga tranquilidad y seguridad a las personas y a las cosas. Cabe aquí, por ejemplo, la concepción que Nogueira denomina estricta y que tiene un marcado acento en la apreciación histórica y finalista del ordenamiento ${ }^{41}$.

Volviendo nuevamente al caso español, si bien el Tribunal Constitucional (TC) atribuye competencia en la materia a los tribunales de justicia y no a la Administración, con ocasión de la discutida sentencia del TC recaída en el caso de la Iglesia de la Unificación, el Tribunal valida la referencia como fundamento a la noción de orden público en tanto no se le otorgue el carácter de cláusula preventiva frente a eventuales riesgos. En lo pertinente, sanciona el TC, "no puede considerarse contraria a la Constitución la excepcional utilización preventiva de la citada cláusula de orden público, siempre que se oriente directamente a la salvaguardia de la seguridad, de la salud y de la moralidad públicas propias de una sociedad democrática, que queden debidamente acreditados los elementos de riesgo y que, además, la medida adoptada sea proporcionada y adecuada a los fines perseguidos" 42 .

Siguiendo la línea expuesta precedentemente, cabe destacar que la naturaleza de la objeción contemplada en la LC, la procedencia de la calificación efectuada por el Ministerio de Justicia y, en general, todo el sistema de registro, control y constitución jurídica de las entidades religiosas, fue objeto de un debate mayor en sede judicial, como consecuencia de la objeción al registro de la Iglesia de Unificación, acaecido el 18 de diciembre de 2003, mediante Resolución $\mathrm{N}^{\circ}$ 5045, del Subsecretario del Ministerio de Justicia.

$\mathrm{Al}$ igual que en el caso español, con numerosas similitudes incidentales, el caso replicó la diferencia producida entre dos instancias, aunque de naturaleza jurisdiccional en el caso chileno. La cuestión expuesta fue la concordancia entre los fines de la entidad religiosa que solicitaba su incorporación en el registro y el orden público, los que, a juicio del Ministerio de Justicia, aparecían en colisión manifiesta, en particular por estimar que la doctrina contenida en los documentos fundamentales de la entidad y que se propone difundir, resultan contrarios al orden público democrático del país, consignado como requisito base a considerar por la Administración para acceder al registro, según lo dispuesto en el art. $19 \mathrm{~N}^{\circ} 6^{\circ}$ de la

servicio de cada sujeto del derecho de libertad religiosa, vale decir en su dimensión individual y colectiva, configurando una barrera contra el abuso del derecho por parte de algunas de estas entidades (Confróntese con Calvo Álvarez, J., citado en Ferrer Ortiz, Javier (1986). El matrimonio canónico en el ordenamiento español. Pamplona (España): EUNSA, p. 115).

Nogueira (2008), p. 26.

Véase González Del Valle (2005), p. 167. 
Constitución Política del Estado. En razón de este fundamento, procedió a objetar el registro ya efectuado. Se trató, en consecuencia, de una objeción basada principalmente en el análisis de los fines religiosos declarados por la entidad y su correspondencia con el orden público y no en el cuestionamiento de la naturaleza religiosa de la entidad, la que, en todo caso, ya contaba con reconocimiento estatal como persona jurídica de Derecho privado, concedida por el último ministro de Justicia del Gobierno del general Augusto Pinochet.

En definitiva, la línea de defensa de la objeción realizada por la Administración en Chile, guardó plena consonancia con lo expuesto por el TSC español, aun cuando en España fue parte de la fundamentación para acoger el registro y en Chile constituyó el fundamento principal para ratificar la sentencia de primera instancia que denegó la acción especial de reclamación frente a la objeción del registro de la entidad religiosa señala$\mathrm{da}^{43}$.

Las consecuencias del fallo, en lo que respecta al tema en análisis, son relevantes. La principal de ellas, sin lugar a dudas, la constituye la validación plena de la práctica de la calificación de las entidades religiosas llevada a cabo por el Ministerio de Justicia, entendiendo que el examen que debe efectuar no se reduce a una mera constatación de los antecedentes aportados, como en el caso de la opinión del TC español, sino que procede una función calificadora que, además de velar por el cumplimiento de los requisitos formales, debe revisar y pronunciarse sobre el contenido o fondo de la solicitud.

¿Se concilia este fallo con lo ya dicho, en el sentido de no proceder el examen sustantivo de los antecedentes de la entidad? Estimamos que ello es efectivo, toda vez que la lectura de la sentencia apunta a la concordancia general de las normas y declaraciones de la entidad con el ordenamiento constitucional, común para todos los sujetos imperados por el Derecho nacional. No es posible, sin embargo, que la administración realice un juicio de discriminación entre la mayor bondad o sintonía del contenido de fe de una entidad religiosa respecto de otra. En concreto, el Ministerio podría pronunciarse respecto de la naturaleza religiosa de la entidad que pretende registrarse, y debería también pronunciarse mediante la objeción si detecta una colisión entre los documentos fundamentales de la entidad religiosa y el ordenamiento constitucional democrático del país ${ }^{44}$.

43 Véase, para el debate sobre la calificación sustantiva en España, la posición contraria de Souto Paz, José (2003) Comunidad politica y libertad de creencias. 2a. edición. Madrid: Marcial Pons, pp. 530-540; a favor, considérese GonZÁlez del VAlle (2005), p. 167.

44 Para una opinión en contrario, considérese la opinión de Ambrosio Rodríguez, quien realizó el alegato ante la E. Corte Suprema en representación de la Iglesia de Unificación, en Rodríguez Quiroz, Ambrosio (2009). "Análisis de algunos aspectos de la Ley 19.638 sobre 
Finalmente, cabe una opinión sobre a quién corresponde efectuar el juicio de discordancia entre los fines de la entidad y el orden público, en particular del sistema democrático. Si bien como principio es correcto que tal ponderación debe realizarse en sede judicial y no administrativa, lo que debería establecer una próxima reforma que perfeccione la LC, lo cierto es que en el sistema chileno actualmente vigente tal aspecto está debidamente resguardado, toda vez que la palabra final siempre la tendrán los tribunales de justicia, ya sea por vía directa en la Corte de Apelaciones o en segunda instancia por la Corte Suprema, como ocurrió efectivamente en el controvertido caso de la Iglesia de Unificación. La Administración, en el caso chileno, si bien advierte la discordancia entre los fines de la entidad y el ordenamiento constitucional vigente, y por ello objeta el registro, no tiene la palabra final sobre el juicio de discordancia, el que siempre será de competencia de los tribunales de justicia.

\section{5) LA OBJECIÓN ADMINISTRATIVA DEL REGISTRO Y LA ACCIÓN DE RE- CLAMACIÓN. FIRMEZA DEL REGISTRO Y SUS EFECTOS JURÍDICOS}

Frente al registro ya efectuado, el Ministerio puede aceptarlo u objetarlo, una vez efectuada la calificación de los antecedentes aportados. Si no objeta el registro, dentro de los 90 días contados desde la anotación registral, o si habiéndose deducido objeción, esta se hubiere subsanado dentro del plazo de 60 días, o si habiéndose deducido la acción de reclamación contemplada en el art. 11, se hubiere rechazado en definitiva la objeción por medio de sentencia ejecutoriada, la entidad podrá proceder a la publicación del extracto, según el procedimiento que se indica más adelante. Este es el procedimiento normal previsto por el legislador, y el que habitualmente tiene lugar en la praxis administrativa.

Excepcionalmente, sin embargo, el Ministerio objetará el registro, siguiendo los fundamentos ya analizados extensamente en los apartados precedentes, mediante resolución fundada, cuando a su juicio faltare algún requisito. Para resolver si objeta o no, dispone de un plazo de 90 días, contados desde la fecha del ingreso de la solicitud de registro, según la constancia estampada en ella por la oficina de partes del Ministerio.

La entidad religiosa afectada por la objeción al registro, puede optar por aceptar la objeción y corregir los aspectos cuestionados, u oponerse a la objeción y abrir consiguientemente la vía judicial mediante la acción especial de reclamación.

constitución jurídica de las iglesias y entidades religiosas". En Alcalde Rodríguez, Enrique y Fábrega Vega, Hugo (coordinadores): Estudios juridicos en homenaje al profesor Pablo Rodríguez Grez. Santiago de Chile: Ediciones Universidad del Desarrollo, pp. 117-128. 
En el primer caso, la entidad se allana a la objeción del Ministerio, y procede a subsanar los defectos advertidos en el proceso de constitución o a adecuar sus estatutos a las observaciones formuladas. Para realizar las adecuaciones indicadas, la entidad dispone de un plazo de 60 días, contados desde la fecha de la resolución respectiva ${ }^{45}$. En el supuesto que el Ministerio estimare insuficiente o derechamente no realizadas las adecuaciones indicadas, el procedimiento debe ser repetido en los plazos previstos, como si se tratara de la primera vez.

En el segundo caso, la entidad puede optar legalmente por oponerse a la objeción formulada por el Ministerio, asumiendo que existen fundamentos suficientes que avalen dicha acción. En este caso, corresponde deducir una acción especial de reclamación, en contra de la resolución que objeta la constitución, ante cualquiera de las Cortes de Apelaciones de la región en que la entidad religiosa tuviere su domicilio, siguiendo para ello el procedimiento y plazos establecidos para el recurso de protección.

Cabe enfatizar que se trata de una acción, en el sentido procesal que la concibe como "una facultad que tienen las personas para provocar el ejercicio de la función jurisdiccional, en orden a la protección, reconocimiento o declaración de un derecho, y que se traduce materialmente en el conjunto de actos procesales que colocan al juez en la situación de tener que dictar sentencia" 46 . No es un recurso, toda vez que este constituye el medio que reconoce la ley a las partes del proceso, para impugnar las resoluciones judiciales, y es especial, porque el restablecimiento del derecho -si así procediere- en una eventual situación de infracción normativa, no puede lograrse por medio de otras acciones dispuestas en el ordenamiento jurídico nacional.

Las normas aplicables son las contenidas en el Auto Acordado de la Corte Suprema de 24 de junio de $1992^{47}$, sobre Tramitación del Recurso de Protección de Garantías Constitucionales (AATRP), las que en lo esencial y pertinente, determinan que la acción se interpondrá por el representante de la entidad o del grupo de personas que promueven su constitución, por escrito, dentro del plazo fatal de treinta días corridos, contados desde la ejecución del acto o la ocurrencia de la omisión o según la naturaleza de estos, desde que se haya tenido noticias o conocimiento cierto de los mismos, lo que se hará constar en autos. En el caso concreto en análisis, el acto que motiva la acción es la resolución que objeta la constitución jurídica de la entidad religiosa, debiendo contabilizarse el

\footnotetext{
45 Confrontar con el art. 11 del DS 303.

46 Nogueira, Humberto (2000). "El derecho de amparo o protección de los derechos humanos, fundamentales o esenciales en Chile: evolución y perspectivas”. En Nogueira Alcalá, Humberto (editor): Acciones constitucionales de amparo y protección: realidad y prospectiva en Chile y América Latina. Talca (Chile): Editorial Universidad de Talca, pp. 11-118, p. 24. 
plazo desde la notificación de la misma ${ }^{48}$. Acogida a tramitación la acción, la Corte ordenará al Ministerio de Justicia que evacúe un informe, al cual se anexarán todos los antecedentes que existan en su poder y que hayan permitido fundar la objeción, fijándole para ello un plazo breve y perentorio ${ }^{49}$. Recibido el informe y sus anexos, "el Tribunal ordenará traer los autos en relación y dispondrá agregar extraordinariamente la causa a la tabla del día subsiguiente, previo sorteo, en las Cortes de Apelaciones de más de una sala" 50 , procediendo a apreciar los antecedentes en conformidad a las reglas de la sana crítica, dictando la sentencia, la que será apelable ante la Corte Suprema, dentro del plazo fatal de cinco días hábiles, contados desde la notificación por el Estado Diario de la sentencia que decide la acción especial de reclamación. En contra de la sentencia que expida la Corte de Apelaciones no procederá el recurso de casación ${ }^{51}$.

El sistema de reconocimiento civil de la asociación religiosa, determina que la entidad gozará de personalidad jurídica de Derecho público por el solo ministerio de la ley, desde que quede firme la inscripción en el registro público ${ }^{52}$. A su vez, se considerará que la inscripción se encuentra firme, desde el momento en que se publica en el Diario Oficial ${ }^{53}$, constituyendo la publicación un acto esencial del procedimiento para la obtención de la personalidad jurídica. Recordemos al efecto de este apartado, que la publicidad es un elemento formal de la existencia de la persona jurídica, requisito que se materializa por su inscripción en el registro público. Los datos contenidos en este son fidedignos y la constancia del registro constituye una prueba legal de su existencia.

El Ministerio de Justicia, mediante providencia emanada del Departamento de Personas Jurídicas, procederá a establecer, a petición de la co-

Confrontar con el artículo 11, inc. tercero de la Ley $\mathrm{N}^{\circ} 19.638$, en concordancia con el $\mathrm{N}^{\circ}$ $1^{\circ}$ del Auto Acordado sobre Tramitación del Recurso de Protección de Garantías Constitucionales (AATRP), modificado por el Auto acordado de 25 de mayo de 2007, publicado en el $D O$ de 8 de junio de 2007.

Confrontar con los números 2 y 3 del AATRP.

$\mathrm{N}^{\circ} 3$, inc. $2^{\circ}$ del AATRP.

Confrontar con los números $5^{\circ}$ y ss., AATRP.

Confrontar con el art. $\mathrm{N}^{\circ} 12$ inc. $1^{\circ}$ del DS 303.

La ley exige la publicación en el Diario Oficial, de un extracto del acta de constitución y de sus modificaciones si las hubiere, que incluya el número de registro o inscripción asignado. La publicación del extracto aparece en el Sumario del día de su publicación, bajo el epígrafe "Ministerio de Justicia" y del título "Entidad(es) Religiosa(s) de Derecho Público, con el propósito de establecer una clara diferenciación de toda otra publicación que aparezca bajo el citado epígrafe. El trámite de publicación deberá efectuarlo la propia entidad religiosa, una vez transcurrido 90 días desde la fecha de la inscripción en el Registro público, sin que el Ministerio hubiere formulado objeciones. Si se hubieren deducido objeciones, habrá que esperar la conformidad del Ministerio respecto de las adecuaciones efectuadas. Si se optó por interponer la acción especial de reclamación, procederá luego del rechazo de la objeción, contenido en sentencia ejecutoriada. Véase Ord. $\mathrm{N}^{\circ} 4569$, del subsecretario de Justicia, de 28 de noviembre de 2000. 
rrespondiente entidad religiosa, la caducidad del plazo legal y la ausencia de trámites pendientes, incluyendo la citada providencia el antecedente del nombre de la entidad y el número de inscripción asignado en el Registro de entidades religiosas de derecho público ${ }^{54}$.

Una interesante apreciación histórica, arroja que la primera publicación correspondió a la entidad religiosa Misión Evangélica Eco Mundial, cuyo extracto fue publicado en el Diario Oficial el 13 de octubre de 2000, habiendo transcurrido 3 meses desde su incorporación en el registro público. Fue seguida poco después, por la publicación del extracto de la Iglesia Evangélica Luterana en Chile, el 11 de noviembre de 2000. Finalmente, la primera entidad registrada, la Iglesia Evangélica Independiente, debió esperar hasta el 21 de agosto de 2001 para efectuar la publicación del extracto, debido a las observaciones efectuadas a su registro, efectuado con el número 00001 el 29 de noviembre de $1999^{55}$.

La firmeza del registro, luego de su publicación, requiere de la ejecución de diversas acciones. En primer lugar, se debe proceder a la confección del extracto por parte de la entidad religiosa ${ }^{56}$, el cual deberá ser autorizado por el notario que suscribió la escritura pública o que redujo a dicha escritura el instrumento privado respectivo. En segundo lugar, debe procederse a la certificación del cumplimiento de las formalidades y requisitos legales para proceder válidamente a la publicación ${ }^{57}$. En tercer lugar, debe realizarse materialmente la publicación en el Diario Oficial ${ }^{58}$, a costa de la entidad religiosa.

En lo que respecta a los efectos jurídicos, desde que quede firme la inscripción en el registro público, la entidad religiosa gozará de personalidad jurídica de Derecho público por el solo ministerio de la ley. Se considerará que la inscripción se encuentra firme, desde el momento en que 
se publica el extracto en el Diario Oficial, circunstancia que se anotará en el Registro de entidades religiosas de Derecho público del Ministerio de Justicia $^{59}$. Si la entidad religiosa no cumple con los requisitos de constitución y dicho propósito finalmente se frustra, vale decir, la entidad no adquiere existencia legal, los actos colectivos que haya realizado, obligarán a todos y cada uno de sus miembros solidariamente ${ }^{60}$.

Ya afirmada la inscripción registral y existiendo por tanto de jure la nueva persona jurídica, las actuaciones concretas futuras de la entidad que colisionen con el ordenamiento, deberán, como es lógico, ser resueltas competentemente en la instancia jurisdiccional respectiva.

Finalmente, cabe consignar dos comentarios respecto de la competencia y oportunidad del control de licitud.

Ya se han entregado los fundamentos que avalan nuestra afirmación en el sentido que es legalmente factible y necesario el pronunciamiento de la Administración, en los dos momentos legalmente establecidos y con el propósito diferenciado que se reconoce a cada uno de ellos.

La advertencia ineludible de una eventual ilicitud, es una acción que debe ejecutar el funcionario, dentro del marco legal y constitucional. Ahora bien, establecido lo anterior, cabe también reiterar que si bien el control de licitud se realiza en sede administrativa, el juicio y la resolución de la discordancia ya advertida, corresponde efectuarlo en sede jurisdiccional, como en los hechos ha ocurrido. Por cierto, no se discute la competencia jurisdiccional para pronunciarse sobre la objeción basada en la eventual inobservancia del ordenamiento en materias tan complejas como la naturaleza religiosa de la entidad, los fines religiosos y, especialmente, la correspondencia o no de estos fines con el ordenamiento. Del mismo modo, no se debería discutir la competencia de la Administración para velar porque el nacimiento a la vida del Derecho de la persona jurídica, se realice en concordancia y armonía con el mismo ordenamiento que le reconoce el especial privilegio de la personalidad de derecho público.

\section{SÍNTESIS CONCLUSIVA}

1. Dentro del procedimiento de constitución jurídica de las entidades religiosas como persona jurídica de derecho público, establecido por la Ley 19.638, cabe distinguir dos instancias de calificación de los antecedentes de las entidades religiosas que pretenden su inclusión en el registro de entidades religiosas de Derecho público que lleva el Ministerio de Justicia. La primera, que antecede al registro pro- 
piamente tal y sin carácter sustantivo, tiene por objeto revisar que la materialización de la entrega de los antecedentes sea completa y suficiente. La segunda instancia de revisión, una vez efectuado el ingreso de la entidad en el registro, constituye la calificación propiamente tal, pudiendo derivar si el análisis de los antecedentes así lo amerita, en la objeción del registro y, eventualmente, en la frustración de la pretensión de constituir jurídicamente a una entidad religiosa.

2. El Ministerio de Justicia debe ejercer una función calificadora que garantice no solo el cumplimiento de los requisitos legales estrictamente formal, sino también el acatamiento y plena observancia del ordenamiento jurídico en un sentido real, material o de fondo por parte de la entidad requirente.

3. Sin perjuicio de la imposibilidad legal absoluta de efectuar valoraciones a partir de una matriz o concepto subjetivo de religión o de una comparación de mayor o menor importancia relativa entre unas y otras por parte de los agentes estatales, sobre los elementos esenciales que constituyen las creencias y la doctrina asumida por la entidad religiosa, es necesario ponderar el mérito religioso de la entidad y analizar la correspondencia de dichos fines con el orden público, pudiendo en todos estos supuestos objetarse el registro ya efectuado, fundando dicha decisión en el respeto al ordenamiento constitucional y legal del Estado, particularmente en la limitación establecida en el artículo $19 \mathrm{~N}^{\circ} 6^{\circ}$ de la Constitución Política, que impone como requisito básico el respeto al orden público, la moral y las buenas costumbres.

4. En aplicación de la perspectiva precedente, la naturaleza de la entidad que requiere el registro deberá ser religiosa, al igual que los fines que declara, los que deberán estar en armonía y no en colisión con el conjunto del ordenamiento jurídico chileno, debiendo en especial cautelar la debida observancia del orden público, la moral y las buenas costumbres.

5. Si bien como principio es correcto que el juicio de discordancia entre los fines de la entidad y el orden público, en particular del sistema democrático, debe realizarse en sede judicial y no administrativa, lo cierto es que en el sistema chileno actualmente vigente tal aspecto está debidamente resguardado, toda vez que la palabra final siempre la tendrán los tribunales de justicia, ya sea por vía directa en la Corte de Apelaciones o en segunda instancia por la Corte Suprema.

\section{BIBLIOGRAFÍA}

- Alcalde Rodríguez, Enrique y Fábrega Vega, Hugo (2009) (coordinadores): Estudios juridicos en homenaje al profesor Pablo 
Rodríguez Grez. Santiago de Chile: Ediciones Universidad del Desarrollo, 504 pp.

- Álvarez Cortina, Andrés y Rodríguez Blanco, Miguel (2006) (coordinadores). La libertad religiosa en España. Granada (España): Comares, 263 pp.

- Cea Egaña, José Luis (1998). Mérito constitucional del proyecto de ley sobre organizaciones religiosas. Santiago de Chile: Instituto Chileno de Estudios Humanísticos, 22 pp.

- Corte Suprema de Justicia (2007). Auto Acordado sobre Tramitación del Recurso de Protección de Garantías Constitucionales (AATRP), modificado por el Auto acordado de 25 de mayo de 2007, publicado en el $D O$ de 8 de junio de 2007.

- Del Picó Rubio, Jorge (2010) (coord.). Derecho de la libertad de creencias. Santiago de Chile: Abeledo Perrot, 200 pp.

(2001). Ley de cultos y documentos complementarios.

Santiago de Chile: KAS/ ICHEH, 176 pp.

- Ferrer Ortiz, Javier (1986). El matrimonio canónico en el ordenamiento español. Pamplona (España): EUNSA, 184 pp.

(2004): Derecho eclesiástico del Estado español. 5a edición. Pamplona (España): Thomson-Civitas, 327 pp.

- Fornés, Juan et alii, (2006). Legislación eclesiástica. 8ª. edición. Cizur Menor (España): Aranzadi, 389 pp.

- González del Valle, José María (2005). Derecho eclesiástico español. Madrid: Thomson-Civitas, 363 pp.

- Gros Espiell, Héctor (1991). La Convención Americana y la Convención Europea de Derechos Humanos. Análisis comparativo. Santiago de Chile: Editorial Jurídica de Chile, 430 pp.

- Llamazares Fernández, Dionisio (2002) (director). Derecho eclesiástico del Estado. Tercera edición. Barcelona (Espańa): Editorial Ariel, 558 pp.

- Ministerio de Justicia (2002): Informe de la Comisión de Estudios para establecer proposiciones de modificación de las normas de la Ley $N^{\circ}$ 19.638 y su Reglamento. Santiago de Chile: inédito.

- Nogueira, Humberto (2000) (editor): Acciones constitucionales de amparo y protección: realidad y prospectiva en Chile y América Latina. Talca (Chile): Editorial Universidad de Talca, 510 pp.

(2008). Derechos fundamentales y Garantias Constitucionales. Santiago de Chile: Librotecnia.

- Palomino Lozano, Rafael (2007). Religión y Derecho comparado. Madrid: Iustel, $417 \mathrm{pp}$.

- Pizarro Wilson, Carlos (2009) (coord.): Estudios de Derecho civil IV. Santiago de Chile: LegalPublishing, 757 pp. 
- Precht Pizarro, Jorge (1998). Un caso de mutación legislativa, la ley de iglesias. Santiago de Chile: Instituto Chileno de Estudios Humanísticos, 20 pp.

- Prieto Martínez, Vicente (2008). Libertad religiosa y confesiones. Bogotá: Editorial Temis/ Universidad de La Sabana, 273 pp.

- Real Academia Española (1992). Diccionario de la lengua española. Vigésima primera edición. Madrid (España): Espasa-Calpe, 1513 pp.

- Salinas Araneda, Carlos (2004). Lecciones de Derecho eclesiástico del Estado de Chile. Santiago de Chile: Ediciones Universitarias de Valparaíso, 474 pp.

- (2001). Sectas y Derecho. Valparaíso: Ediciones Universitarias de Valparaíso, $417 \mathrm{pp}$.

- Schwabe, Jürgen (2003). Cincuenta años de Jurisprudencia del Tribunal Constitucional alemán. Traducción de Anzola, Marcela. Montevideo: Konrad Adenauer Stiftung, 501 pp.

- Souto Paz, José (2003). Comunidad política y libertad de creencias. 2a. edición. Madrid: Marcial Pons, 667 pp. 